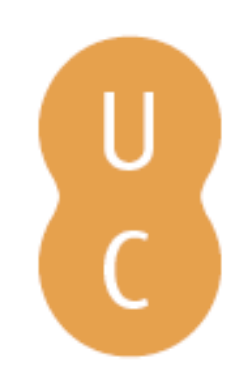

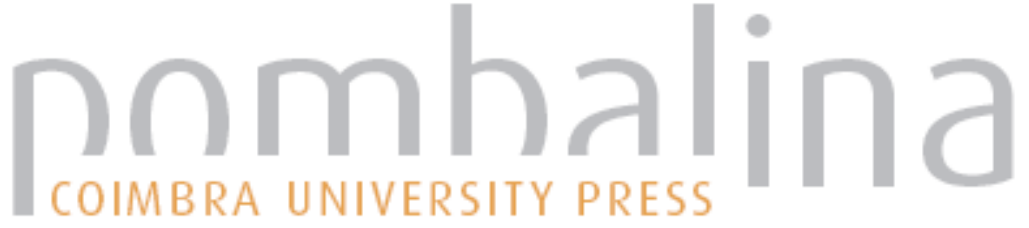

\section{Utopia e distopia na sociedade das abelhas}

\author{
Autor(es): $\quad$ Oliveira, Francisco de
}

Publicado por: Imprensa da Universidade de Coimbra

URL

persistente: URI:http://hdl.handle.net/10316.2/32061

DOI: $\quad$ DOI:http://dx.doi.org/10.14195/978-989-26-0499-2_13

Accessed : $\quad$ 26-Apr-2023 01:09:15

A navegação consulta e descarregamento dos títulos inseridos nas Bibliotecas Digitais UC Digitalis, UC Pombalina e UC Impactum, pressupõem a aceitação plena e sem reservas dos Termos e Condições de Uso destas Bibliotecas Digitais, disponíveis em https://digitalis.uc.pt/pt-pt/termos.

Conforme exposto nos referidos Termos e Condições de Uso, o descarregamento de títulos de acesso restrito requer uma licença válida de autorização devendo o utilizador aceder ao(s) documento(s) a partir de um endereço de IP da instituição detentora da supramencionada licença.

Ao utilizador é apenas permitido o descarregamento para uso pessoal, pelo que o emprego do(s) título(s) descarregado(s) para outro fim, designadamente comercial, carece de autorização do respetivo autor ou editor da obra.

Na medida em que todas as obras da UC Digitalis se encontram protegidas pelo Código do Direito de Autor e Direitos Conexos e demais legislação aplicável, toda a cópia, parcial ou total, deste documento, nos casos em que é legalmente admitida, deverá conter ou fazer-se acompanhar por este aviso.

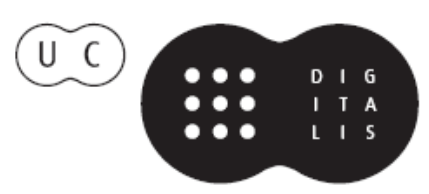


Maria de Fátima Silva

Coordenação

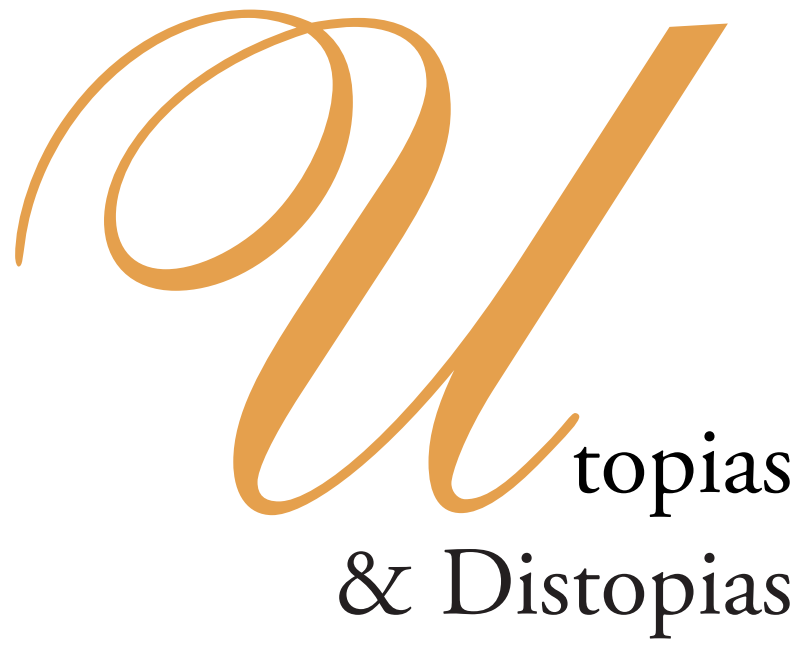




\section{COORDENAÇÃO EDITORIAL \\ Imprensa da Universidade de Coimbra \\ Email: imprensauc@ci.uc.pt \\ URL: http://www.uc.pt/imprensa_uc}

\section{CONCEPÇÃO GRÁFICA}

António Barros

Pré-IMPRESSÃo

Tipografia Lousanense, Lda.

EXECUÇÃO GRÁFICA

Tipografia Lousanense, Lda.

ISBN

978-989-8074-74-4

DEPósito LEGAL

289002/09

OBRA PUBLICADA COM O APOIO DE:

Centro de Estudos Clássicos e Humanísticos

Faculdade de Letras da Universidade de Coimbra

FCT Fundação para a Ciência e a Tecnologia

MINISTÉRIO DA CIÊNCIA, TECNOLOGIA E ENSINO SUPERIOR Portugal 
Maria de Fátima Silva

Coordenação
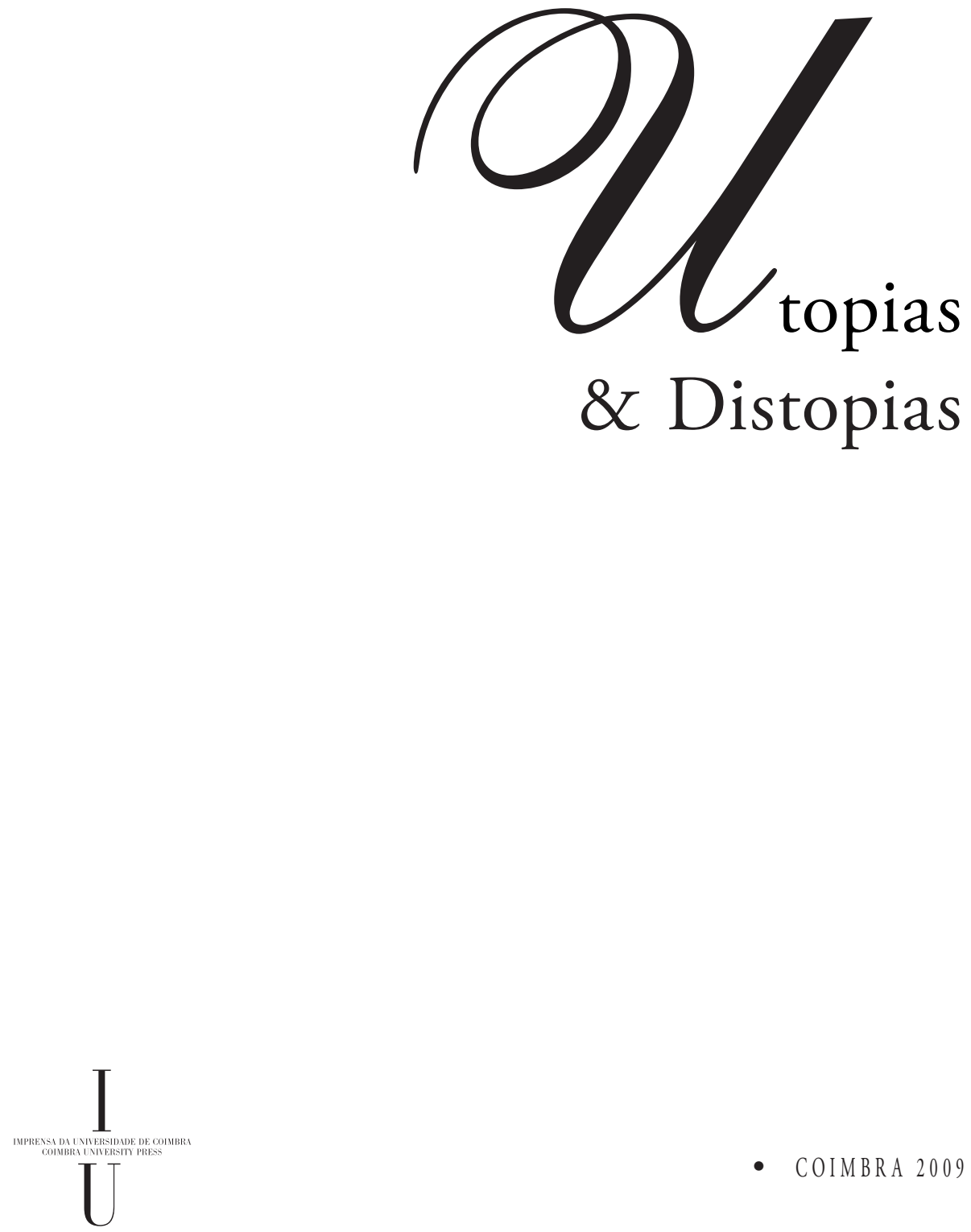

- colmbra 2009 



\section{Francisco de Oliveira}

\section{UTOPIA E DisTOPIA NA SOCIEDADE DAS ABELHAS ${ }^{1}$}

Atque etiam in bestiis uis naturae perspici potest 'Pois também nos animais se pode descortinar a força da natureza'

Cícero, Tratado dos Limites, 3.62

\section{Resumo}

Entre os modelos de sociedades animais que a natureza oferece à imitação dos humanos, escolhi a sociedade das abelhas para estudar como o tema é tratado em autores do final da República e Principado - Varrão, Virgílio, Séneca, Columela, Plínio o Antigo, com breve passagem por fontes gregas, em especial Aristóteles.

Palavras-chave: abelha, animal, apicultor, Aristóteles, Cícero, civilização, Columela, distopia, Hesíodo, homem, monarquia, monocracia, natureza, Platão, Plínio o Antigo, Plutarco, sedentarismo, Séneca, sociedade, Teógnis, trabalho, utopia, Varrão, Virgílio, Xenofonte.

\section{Pressuposto metodológico}

Para o presente objectivo, não se torna necessário entrar em linha de conta com eventual influência de concepçóes capazes de alicerçar filosoficamente eventuais aproximaçôes, metafóricas ou simbólicas, entre espécie humana e outras espécies animais. Bastaria recordar que "the humanisation of animals is a familiar feature of all agrarian societies"2.

Assim, mais do que falarmos eventualmente numa Thierpsychologie como espelho oferecido aos humanos pela natureza, podemos inclusive pensar que os mesmos animais, enquanto símbolos de comportamentos, podem ter-se avizinhado da esfera humana

\footnotetext{
1 Trabalho realizado no âmbito do projecto de investigação do Centro de Estudos Clássicos e Humanísticos da Universidadde de Coimbra (CECHUC), com financiamento da FCT.

2 M. Grosse, 2006, p. 139.
} 
simplesmente porque com ela partilhavam o espaço e o quotidiano, fornecendo-lhe ao mesmo tempo a força do exótico, da exemplaridade, do imaginário ${ }^{3}$.

Tal como escreve Pollard, a propósito das histórias sobre aves na Grécia, folclore e fábula oferecem inúmeros exemplos que, desde Hesíodo, contêm uma vertente de moralização ${ }^{4}$.

Nos autores latinos estudados está presente uma característica bem romana, a crermos em autores como Aymard: em Roma, "la Tieréthologie apparaît... comme une variante, un duplicata, parfois même un modèle de l'éthique humaine”.

Ainda assim, recordarei dois autores antigos, Cícero e Plutarco. O primeiro defende a primazia do instinto gregário inato como base da sociedade humana, a exemplo do que se passa com a sociedade das abelhas, que não se congregam para construir favos, mas que constroem favos por serem animais congregáveis por natureza ${ }^{5}$. Quanto a Plutarco (493e), nele se diz que a natureza mantém pura a especificade dos animais, sem mistura e absolutamente simples, ao contrário dos humanos, onde há desvios.

\section{Platáo}

Recordemos, em breve apontamento, que Platão se refere às abelhas como exemplo claro de sociedade politicamente organizada em monarquia, apresentando três tópicos muito interessantes sob o ponto de vista que nos interessa.

Um deles é que as abelhas-mestras foram criadas com a finalidade de exercer a governação política e salvaguardar o bem-comum, servindo de modelo aos sábios, que estão destinados a ser reis (R. 520b):

"Mas a vós, nós formámo-vos, para vosso bem e do resto da cidade, para serdes como os chefes e os reis (hegemonas te kai basileas) dos enxames de abelhas, depois de vos termos dado uma educaçáo melhor" ${ }^{6}$.

Noutro passo, através de uma visão antropomórfica, Platão compara a fundação de um novo enxame à instalaçáo de uma colónia (Pl. Plt. 293d)7:

"E se, em nome do bem da cidade, esses governantes procedem a operaçóes de limpeza, ordenando homicídios ou condenações ao exílio, se enviam os cidadãos para colónias como se fossem enxames de abelhas, de modo a tornar a cidade mais pequena, ou se, pela introdução na mesma de novos indivíduos, a quem conferem a cidadania, a fazem crescer?”.

Finalmente, também se concebe a realeza animal em termos de modelo de monarquia primitiva, onde o mais alto e mais belo naturalmente se impunha como governante, embora num quadro de soberania limitada (Pl. Plt. 301e):

\footnotetext{
3 Ver Toynbee, 1973, p. 50 ss., sobre o elefante enquanto símbolo que representa África na numismática; pp. 63-64 sobre o leão; pp. 206-208 sobre o golfinho; pp. 233-236 para a serpente; Plínio recorda os animais usados nas insígnias militares romanas (Nat.10.16).

4 Pollard, 1977, p. 182.

5 Cic. Off. 1.157: Atque ut apium examina non fingendorum fauorum causa congregantur, sed, cum congregabilia natura sint, fingunt fauos, sic homines...

6 Trad. de M. H. Rocha-Pereira, Platão, A República, Lisboa.

7 A tradução dos passos do Político é de Carmen Soares, Lisboa, 2008.
} 
"Mas uma vez que - conforme dissemos - no momento presente o rei das cidades dos homens não é como o que produzem as colmeias (à partida único e superior em corpo e alma), é necessário - ao que parece - que as pessoas se reúnam para redigir as leis, seguindo a orientação da mais verdadeira das constituiçôes.”.

\section{Xenofonte}

Lancemos também um olhar para a Ciropedia de Xenofonte, obra que traça a figura de um monarca ideal corporizado na figura de Ciro.

Aí, depois de dirigir aos Medos palavras de agradecimento pelo apoio passado e de lhes deixar liberdade para agir livremente no futuro, sem perderem a sua gratidão, Ciro ouve o primeiro interlocutor dizer que todos desejam acompanhá-lo de livre vontade (hekontes akolouthein; X. Cyr. 5.1.24-25):

24. “... Parece-me que por natureza foste destinado a ser rei (basileus), não menos do que, num enxame, o destinado a ser chefe das abelhas (melitton hegemon). A este, de facto, sempre as abelhas obedecem voluntariamente; onde quer que ele se estabeleça, nenhuma daí se afasta; se sai para algum lado, nenhuma fica para trás, tão forte é o amor delas por estarem às suas ordens. 25. Pois também perante ti estes homens me parecem ter exactamente o mesmo comportamento.".

Tal retrato de Ciro permite enfatizar o amor dos súbitos e o princípio da submissão e obediência, traço com frequência relacionado com uma monarquia de tipo oriental.

Outro aspecto de grande curiosidade, agora em $E c$. 7.17-32, é ver como a esposa é comparada a uma abelha-mestra, à qual compete permanecer dentro de casa e vigiar as provisóes, num passo onde a terminologia transita de he hegemon melitta para he ton melitton hegemon, no pressuposto de que a abelha-chefe ou a chefe das abelhas é do sexo feminino ${ }^{8}$.

\section{Aristóteles}

Na História dos Animais, o próprio Estagirita refere que a matéria é controversa, em especial quanto à procriação. Uma das teorias referidas considera que são os chefes que geram (HA 553a: tiktein tous hegemonas) e que, por isso, alguns lhes chamam mães; deles existem duas espécies: os melhores, fulvos; os outros, negros. Nasceriam 6 ou 7 hegemones. Os reis e chefes (basileis kai hegemones) têm aguilhão mas não picam, o que leva alguns a considerar que o não têm. E Aristóteles acrescenta $(H A$ 553b):

${ }^{8}$ De qualquer forma, como observa Wilkinson, 1969, p. 264, he hegemon pode simplesmente estar por he hegemone melitta; cf. X. HG 3.28 (o povo aglomera-se à volta do rei como as abelhas ao redor da rainha); Semónides, fr. 7W, p. 83 ss., vê na mulher feita a partir da abelha alguém que "sobressai no meio das outras mulheres" (trad. de Frederico Lourenço, Poesia Grega de Álcman a Teócrito. Lisboa, 2006); ver paralelo com o epíteto hegemone de Ártemis e de Afrodite. 
"Existem vários chefes em cada colmeia, e não um apenas. É que os enxames que não têm chefes em número suficiente acabam por morrer, não por serem anárquicos, mas, como dizem, por serem necessários para o nascimento (genesis) das abelhas; e também se desfazem se tiverem chefes em demasia (polloi).”.

Já em Genealogia dos Animais as abelhas distinguem-se de outros insectos por terem algo de divino ( $G A$ 761a: theion) e por a sua reprodução levantar muitas teorias ( $G A 759$ a e $760 \mathrm{a})$, as quais são enumeradas por Aristóteles: que abelhas, zângãos e chefes ou reis são gerados sem cópula; que os zângãos são do sexo masculino e as obreiras do sexo feminino; ou que a realidade é o inverso dessa atribuição. Mas as aporias não faltam: nem as obreiras podem ser de sexo feminino por terem aguilhão, e a natureza só consente o uso de armas ao sexo masculino; nem os zângãos podem ser do sexo masculino porque cuidam das crias, e a natureza destina tal trabalho ao sexo feminino.

Quanto às várias e díspares teorias sobre a procriação das abelhas, vem Aristóteles, de forma abrupta, a valorizar a observação sobre a teoria, concluindo ( $G A 760 \mathrm{a}$ ): "Todavia, e uma vez que tal é negado pelos que se dedicam à apicultura, só resta que os reis se geram a si próprios e às obreiras".

Em relaçáo à tripla descendência destes hegemones (termo mais usado do que basileis), o produto tem de se diferenciar por pequenas particularidades, como seja o aguilhão, que foi dado aos chefes, não aos zângãos, que igualam os chefes em tamanho; e se as obreiras têm aguilhão, são todavia dotadas de tamanho inferior aos chefes. Se tais diferenças não existissem, toda a geração seria de chefes (GA 760a).

Como parece óbvio, a lógica e acaso o género gramatical dos termos hegemon e basileus constituiram o grande obstáculo epistemológico para Aristóteles explorar a hipótese de hegemon e basileus serem do sexo feminino e os zângãos do sexo masculino.

A excepcionalidade das abelhas permite ainda um louvor à natureza que criou os reis para a reproduçáo, tarefa que implica permanecerem confinados dentro da colmeia, embora sejam as obreiras que, quais amas, alimentam as crias e os progenitores; é de resto esta filiação que está na base da obediência do enxame ( $G A 760 \mathrm{~b})$ :

"Há consenso quanto a obedecerem aos reis pelo facto de a geração das obreiras depender deles (se assim não fosse, nenhuma lógica teria o que sucede em relação à sua hegemonia), e não os deixam fazer nenhum trabalho, na medida em que são os seus progenitores ... O facto de alguns poucos chefes (oligous hegemonas) gerarem muitas obreiras...”.

Aristóteles não deixa de apontar uma vantagem prática na reprodução assexuada: todos os insectos que são gerados por meio de cópula, gastam nela muito tempo ( $G A$ 761a), como quem diz que às abelhas fica mais tempo livre para trabalhar ${ }^{9}$.

O rei aparece como garantia da coesão da colmeia (HA 624a), sendo transportado pelo enxame quando não pode voar: "Se morrer, o enxame morre também" 10 .

\footnotetext{
${ }^{9}$ Entre as várias explicaçóes para a reprodução das abelhas Aristóteles (HA 553a 16-25) inclui a hipótese de cópula do zăngão com a obreira.

10 Trad. de M. F. Silva, Aristóteles, Obras Completas. História dos Animais. II. Lisboa, 2008; ver também $H A 625$ b para a aglomeração das abelhas à volta do rei.
} 
Quanto à existência de vários reis, observe-se que é dito que nascem 6 ou 7 ( $H A$ $553 \mathrm{~b})$ e que há duas espécies, uma de boa qualidade (HA 624b), outra de má (HA 625a). Deduz-se que, quando um enxame sai do cortiço, e é de supor que se trate de um enxame novo, se o mesmo se juntar a outro, mata o rei se este o seguir, o que supóe que não há partilha de poder ( $H A$ 625b).

Finalmente, falando de trabalho, Aristóteles enfatiza a hierarquia de tarefas e a diligência, pois as obreiras começam a trabalhar três dias depois de nascerem (625b-627b), mas também sobreleva o perigo da indolência, sendo por isso vantajosa a presença de um pequeno número de zângãos, que as tornam mais laboriosas

Deste modo, mais do que o emblema do trabalho, subjaz o tema da boa organização de tarefas cooperativas, a par com os princípios da chefia tendencialmente única e da não utilização do aguilhão por parte dos chefes ou reis (HA 626a). Algumas destas ideias não são vincadas de forma taxativa porque Aristóteles se vê envolvido em muitas controvérsias que não sabe compatibilizar.

\section{Varrão}

Passando rapidamente pela reprodução das abelhas (3.16.4: nascem em parte de abelhas, em parte por bugonia), a personagem Ápio logo se encaminha para os aspectos do seu comportamento, afirmando que elas não são de natureza solitária, antes como os humanos, e que formam uma societas operis et aedificiorum 'comunidade de trabalho e de habitaçáo', e são dotadas de ratio atque ars, servindo de modelo e orientação didáctica para o homem na sua preocupação com a organização das tarefas, com a construção da sua morada, com a garantia dos abastecimentos. Poderíamos ver aqui a perspectiva de um comunitarismo que é um traço comum de muitas utopias antigas.

A visão antropomórfica acentua-se com o recurso a terminologia da organização social e génese da sociedade (3.16.6-7).

6. Haec ut hominum ciuitates, quod hic est et rex et imperium et societas. [Quod] secuntur omnia pura... 7. neque tamen nescia suae inbecillitatis.

6. "Estas são como as cidades dos homens, pois nelas também há um rei, um poder e uma comunidade. O facto é que procuram tudo o que é puro...". 7. "E a abelha não ignora a sua debilidade.”.

Este passo introduz o tema da constituição política, de cariz monárquico, com sugestão da existência de um pacto social, elogio da organização e do trabalho, do amor ao rei e da posição superior e agregadora deste, incluindo uma tonalidade marcial e a marca de uma forte disciplina, bem como uma eventual coloração romana na referência às colónias (3.16.8-9):

8. Regem suum secuntur, quocumque it, et fessum subleuant, et si nequit uolare, succollant, quod eum seruare uolunt... 9. Omnes ut in exercitu uiuunt atque alternis dormiunt et opus faciunt pariter et ut colonias mittunt, iique duces conficiunt quaedam ad uocem ut imitatione tubae. Tum id faciunt, cum inter se signa pacis ac belli habent. 
8. "Seguem o seu rei, para onde quer que ele vá, e, quando está cansado, apoiam-no e, se não consegue voar, carregam com ele, pois querem conservá-lo...". 9. "Vivem todas como num exército e revesam-se para dormir e entregam-se ao trabalho por igual e como que enviam colónias, e os seus chefes transmitem certas ordens pela voz, como que imitando uma trombeta. Então elas cumprem a ordem, trocando entre si sinais de paz e de guerra.".

Pela boca de Mérula, outra personagem do diálogo, Varrão aflora depois alguns ideários ético-políticos nos conselhos dados ao apicultor ou mellarius (3.16.18):

... ut animaduertat ne reguli plures existant; inutiles enim fiunt propter seditiones. [Cum] et quidam dicunt, tria genera cum sint ducum in apibus, niger ruber uarius, ut Menecrates scribit, duo, niger et uarius, qui ita melior, ut expediat mellario, cum duo sint <in> eadem aluo, interficere nigrum, cum sit cum altero rege, esse seditiosum et corrumpere aluom...

“... tome cautela para não existirem dois jovens reis; tornam-se inúteis, devido às sedições. Como afirmam vários autores, existem três espécies de chefes nas abelhas - o negro, o vermelho e o matizado; como escreve Menécrates, existem dois - o negro e o matizado, que é de tal modo melhor que ao apicultor convém, quando ambos estáo na mesma colmeia, matar o negro, que é sedicioso e corrompe a colmeia quando está com um segundo rei...”.

Este passo mostra de forma clara que o modelo de governação não consente partilha, e que o poder monárquico é atribuído ao melhor e aparentemente mais belo, por ter mais colorido. De qualquer modo, a superioridade do homem sobre o animal é assinalada pela intervençáo salutar do apicultor (mellarius), com vocabulário reminiscente da agitação social do final da República (seditiones, seditiosum).

Também a descrição da saída de um novo enxame no início da primavera assume tonalidade claramente itálica e política (3.16.29-30):

Cum examen exiturum est, quod fieri solet, cum adnatae prospere sunt multae ac progeniem ut coloniam emittere uolunt, ut olim crebro Sabini factitauerunt propter multitudinem liberorum, huius quod duo solent praeire signa, scitur.

"Quando um enxame está para sair, o que costuma acontecer quando as crias são felizmente muitas e elas querem enviar a sua descendência como que para uma colónia, como outrora costumavam fazer os Sabinos por causa do grande número de filhos, isso é coisa que se percebe, porque costuma haver dois sinais a servir de presságio.”.

De facto, não só existe uma visão antropomórfica e de natureza militar, como ainda tal saída é ilustrada pela evocação do uer sacrum dos Sabinos, um ritual de primavera ligado à necessidade de encontrar terras para um excesso demográfico das regióes montanhosas e pobres que os mesmos habitavam. Trata-se de um procedimento retórico, o uso de um exemplo romano, com o qual Varrão reforça a eficácia persuasiva do exposto. 


\section{Virgílio}

Na Geórgica IV, a descrição da sociedade das abelhas começa logo pelo situs, de acordo com a tradição etnográfica, o que reforça a sua exemplaridade para a humanidade $(G .4 .1-5)^{11}$ :

Protinus aerii mellis caelestia dona exsequar; hanc etiam, Maecenas, adspice partem.

Admiranda tibi leuium spectacula rerum, magnanimosque duces totiusque ordine gentis mores et studia et populos et proelia dicam.

"De seguida, os celestes dons do mel que caem do céu, eu vou tratar. Também a esta parte, ó Mecenas, dá atenção.

Para ti admiráveis espectáculos de seres leves, e chefes magnânimos e, de toda essa nação, por ordem, costumes e paixôes e povos e combates vou expor.”.

Afloram aqui vários temas recorrentes nas fontes que analisamos: o carácter divino, excepcional e exemplar das abelhas, a sua liderança, a sua organização e costumes, os elementos disfóricos.

A vizinhança das abelhas ao conceito de divindade ${ }^{12}$ é vertida, embora sob a forma de citaçáo de outras opinióes, com uma tonalidade estóica muito conveniente à argumentação ( $G$. 4.219-223):

His quidam signis atque haec exempla secuti esse apibus partem diuinae mentis et haustus aetherios dixere: deum namque ire per omnis terrasque tractusque maris caelumque profundum;

binc pecudes, armenta, uiros, genus omne ferarum...

"Com tais sinais e tomando tais exemplos, disseram alguns que as abelhas têm uma parcela da mente divina e emanaçóes etéreas; que deus está realmente presente em todas as terras e vastidôes do mar e no alto céu; daí os rebanhos, as manadas, os homens, todo o tipo de feras...”.

A este passo subjazem vários temas, desde logo a inserção do homem no reino animal, justificação científica para que ele possa tomar o animal como exemplo de comportamento. Depois, o da divindade das abelhas, que já vislumbrámos em Aristóteles, a sugerir imortalidade (G. 4.219-227; cf. 281-314) ${ }^{13}$.

Quanto à organização social, comecemos por reparar num dos passos que melhor ilustram a nossa problemática (G. 4.153-168):

\footnotetext{
11 Putnam, 1979, p. 237: "bees... become a compelling analogy for humankind"; p. 242: "Yet man is a vital entity in their lives".

12 Sobre a relação das abelhas com Júpiter, ver G. 4.149-152; cf. Hesíodo, Theog. 453 ss.; Thomas, p. 175 , ad 150-152.

13 Para o tema da divindade das abelhas com topo literário, cf. Thomas, pp. 186-188, ad 219-227; Mynors 1994, ad 219-227.
} 
Solae communia natos, consortia tecta urbis habent magnisque agitant sub legibus aeuom et patriam solae et certos nouere Penatis

uenturaeque hiemis memores aestate laborem experiuntur et in medium quaesita reponunt. Namque aliae uictu inuigilant et foedere pacto exercentur agris; pars intra saepta domorum narcissi lacrimam et lentum de cortice gluten prima fauis ponunt fundamina, deinde tenacis suspendunt ceras; aliae spem gentis adultos educunt fetus; aliae purissima mella stipant et liquido distendunt nectare cellas. Sunt quibus ad portas cecidit custodia sorti inque uicem speculantur aquas et nubila caeli aut onera accipiunt uenientum aut agmine facto ignauom fucos pecus a praesepibus arcent.

"Só elas têm os filhos em comum, tectos de uma cidade colectiva, e sob grandes leis passam a vida; pátria só elas conhecem e Penates fixos,

e, com a memória do inverno futuro, no verão dedicam-se ao trabalho e colocam à disposição de todos a colheita.

De facto, umas tratam dos alimentos e, pelo acordo celebrado, trabalham nos campos; uma parte delas, no interior das casas, coloca as lágrimas do narciso e o pegajoso visco das cascas como primeiro alicerce para os favos, a seguir suspende as ceras aderentes; outras conduzem a esperança da nação, as crias já crescidas; outras, méis puríssimos acumulam e impregnam as celas de néctar transparente. A algumas coube em sorte estarem de guarda aos portôes e, à vez, observam as chuvas e as nuvens do céu ou recebem os fardos das que chegam ou, em formação militar, repelem dos cortiços os zângãos, rebanho de poltrôes.”.

Neste excerto, três ideias-chave se apresentam: o sistema político, a ideia de sedentarismo e civilização, a organização do trabalho.

O tema do labor das abelhas, cuja tenacidade é marcada pelo elenco de verbos activos e pela construção frásica centrada em algumas anáforas (aliae), está aqui ligado à ideia de que as abelhas possuem uma visão do futuro, na verdade uma forma de memoria e sapientia que classificamos como prouidentia, mas passa também pela divisão equitativa e democrática das tarefas (atente-se na ideia epicurista de pacto social, em foedere pacto, e na tiragem à sorte das tarefas, em cecidit... sorti) e até pela rotatividade (v. 166: in uicem), com o consequente usufruto comunitário da produção. Pelo meio, sugere-se corpo social solidário (v. 167: onera accipiunt uenientum) e assinala-se uma tonalidade marcial reiterada em ad portas custodia, agmine facto / $\operatorname{arcent}^{14}$.

${ }^{14}$ Sobre os aspectos militares e guerreiros da sociedade das abelhas, ver P. Johnston, 1980, p. 108 ss. 
O trabalho das abelhas já fora descrito em termos semelhantes e com idênticos recursos estilísticos, com uma série de verbos de acção a vincar a extrema dedicação das abelhas (G. 4.39-41: linunt, explent, seruant, em forma trimembre que reencontramos nos v. 53-54: peragrant, metunt, libant) e um verdadeiro espírito de emulação (G. 4.38: certatim), com alegria (v. 55: laeti) e frenesim (G. 4.53-55: continuo ... leues).

Ambas as descrições deixam entrever uma verdadeira paixão pelo trabalho ( $G$. 4.169: Feruet opus) ${ }^{15}$ e um instinto de acumulação de bens que são característicos da ética da Idade de Júpiter ${ }^{16}$, bem como uma distribuição hierarquizada e racional de funçóes, tendo em conta a idade e a optimização do esforço ( $G$. 4.178 ss.):

...munere quamque suo. Grandaeuis oppida curae,

et munire fauos et daedala fingere tecta.

At fessae multa referunt se nocte minores,

crura thymo plenae (...)

Omnibus una quies operum, labor omnibus unus ${ }^{17}$ :

mane ruont portis; nusquam mora ${ }^{18}$;

“...cada uma na sua tarefa. Para as mais velhas, os encargos são

o ópido e construir favos e moldar tectos engenhosos.

Mas as mais novas recolhem-se cansadas, noite dentro,

com as patas cheias de tomilho (...)

Para todas é comum o repouso das canseiras, o trabalho para todas é comum:

pela manhã precipitam-se portas fora; nunca há atraso.

Mas se o trabalho garante o sustento, resta a propagação da espécie ( $G$. 4.55-57), que se faz, como em Aristóteles, de forma assexuada (G. 4.197-202) ${ }^{19}$ :

Illum adeo placuisse apibus mirabere morem,

quod nec concubitu indulgent nec corpora segnes

in Venerem soluont aut fetus nixibus edunt!

uerum ipsae e foliis natos et suauibus herbis

ore legunt, ipsae regem paruosque Quirites

sufficiunt aulasque et cerea regna refingunt.

"Causará admiração o costume grato às abelhas

de não consentir acasalamento e não amolentar os corpos indolentes

com prazeres de Vénus, nem passar por dores de parto!

$\mathrm{Na}$ verdade por si mesmas recolhem as crias das folhas

200

15 Cf. A. 1. 436, comparando o trabalho dos Tírios com o das abelhas (feruet opus) e 4.407, com o das formigas (opere omnis semita feruet).

16 Verg. G. 4.177: innatus apes amor urget habendi; 4.205: tantus amor florum et generandi gloria mellis; cf. Thomas, 1988, p. 181 ad 177 e p. 176 ad 150-152: a recompensa de Júpiter às abelhas foi uma natureza caracterizada pelo trabalho; antes, o mel era produzido espontaneamente. Mynors, 1994, ad 176-178: os poetas consideram negativo o desejo de riquezas.

17 Cf. Verg. G. 4.212: Rege incolumi, mens omnibus una est.

${ }^{18}$ Cf. Verg. G. 3.110 nec mora nec requies; 4.548 haud mora, continuo matris praecepta facessit.

19 Para a interpretação da ausência de vida sexual, ver M. Putnam, 1979, p. 261 ss. 
e das tenras ervas, com a boca, por si mesmas procriam um rei

e pequenos Quirites e refazem palácios e um reino de cera.".

Controvérsia à parte, a questão da reprodução implica um dos objectivos políticos mais marcantes, a estabilidade e a consequente eternidade da raça ${ }^{20}$, a afirmar-se aqui como modelo do Estado romano (G. 4.206-209):

Ergo ipsas quamuis angusti terminus aeui excipiat (neque enim plus septima ducitur aestas), at genus immortale manet, multosque per annos stat fortuna domus, et aui numerantur auorum.

"Assim, embora a si mesmas as acolha um termo de vida de duração limitada (é que não vivem mais de sete veróes), porém a raça permanece imortal e por muitos anos se mantém a fortuna da casa, e contam-se os avós dos avós.".

Passemos agora às ideias, conexas, de sedentarismo e civilização. O sedentarismo é logo assinalado em G. 4.8 (sedes statioque 'morada permanente'; cf. v. 65-66), ideia reforçada pelo uso de patria e sobretudo de Penates (v. 155: certos Penatis; cf. v. 43), domus (v. 159, 209), tectum (v. 187) thalamus (v. 189), urbs (v. 193, cidade com suas muralhas).

O terceiro ponto refere-se à organizaçáo política e em especial à ideia de monocracia, onde o rei aparece como garantia da coesáo social do enxame, governando pelo amor e pela justiça, como espelho dos subordinados. Em Virgílio não deixa de estar presente o contraste ético entre bom e mau rei, contraste que molda as características dos respectivos súbditos, os quais imitam a imagem do seu governante, que para eles funciona como modelo, inclusive no aspecto físico ( $G$. 4.95-102):

Vt binae regum facies, ita corpora plebis:

namque aliae turpes horrent, ceu puluere ab alto horridus quom uenit et sicco terram spuit ore uiator aridus; elucent aliae et fulgore coruscant ardentes auro et paribus lita corpora guttis. Haec potior suboles: hinc caeli tempore certo dulcia mella premes...

"Tal como é diferente o aspecto dos reis, assim o físico da plebe: umas, sujas, estão cheias de pêlos, qual caminhante, horrendo, ressequido, que vem cheio de pó atmosférico e cospe terra da boca seca; reluzem as outras coruscantes com seu fulgor, cintilantes de ouro e gotas simétricas nos seus corpos fulgentes. Esta descendência é a melhor; desta, em altura certa do ano, tirarás doce mel...".

${ }^{20}$ Cf. P. Johnston, 1980 , pp. 93-94 para a relação entre eternidade da raça e cuidado com as crias. 
De facto, o toque de beleza das obreiras que cintilam, à imitação do seu rei, deixa entrever que a própria escolha deste para reinar se apoia nesse atributo, que gera nas súbditas uma devoção total. Esta concepção pode denotar a visão de uma sociedade primeva, próxima da idade do ouro ${ }^{21}$, com uma monarquia superior a monarquias estrangeiras e bárbaras $(G .4 .210-218)^{22}$ :

Praeterea regem non sic Aegytus et ingens

Lydia nec populi Parthorum aut Medus Hydaspes

obseruant. Rege incolumi mens omnibus una est;

amisso rupere fidem constructaque mella

diripuere ipsae et cratis soluere favorum.

Ille operum custos, illum admirantur et omnes

circumstant fremitu denso stipantque frequentes

et saepe attollunt umeris et corpora bello

obiectant pulchramque petunt per uolnera mortem.

"Além disso, pelo rei, nem o Egipto nem a ingente Lídia

nem os povos Partos nem o Medo Hidaspes têm

tal respeito. Com o rei incólume, todas têm um único pensamento;

se se perde, rompem o contrato e destroem elas próprias o mel

acumulado e desfazem os alvéolos dos favos.

É ele o supervisor dos trabalhos, é a ele que admiram e todas

o rodeiam com um ruído contínuo e em magote o escoltam

e amiúde o amparam com seus ombros e na guerra protegem-no

com seus corpos e nas feridas procuram uma morte bela.".

Observe-se que a ideia de sacrifício voluntário, dada pela ocorrência de pulchram mortem 'uma bela morte', não se encontra em Varrão, para além de Virgílio acentuar o paralelismo com o ambiente humano.

Num outro trecho onde a legitimação do poder monárquio também é de cariz militar, tal antropocentrismo reveste-se de colorido romano ${ }^{23}$ e implica condenação à morte dos reis de qualidade inferior, para favorecer a monocracia ( $G$. 4.88-90):

Verum, ubi ductores acie reuocaueris ambo,

deterior qui uisus, eum, ne prodigus obsit,

dede neci; melior uacua sine regnet in aula.

"E, mal fizeres retroceder ambos os comandantes,

ao que se mostrou pior, para que esse pródigo não seja obstáculo,

dá-lhe a morte; deixa o melhor reinar num palácio sem partilha.".

Esta violência, mais do que ónus do trabalho, é um dos elementos disfóricos do tratamento em Virgílio, sem prejuízo da ligação das abelhas a um ideal idílico ${ }^{24}$,

\footnotetext{
${ }^{21}$ P. Johnston, 1980, p. 61 relaciona o dourado das abelhas como a idade de ouro.

22 Mynors, 1994, ad 210-211: mais do que realidade histórica, o autor pretende evocar o despotismo oriental.

23 Para a relação alegórica de alguns passos com as guerras civis romanas, ver discussão em Miles, 1980, pp. 232-236 e M. Putnam, 1979, p. 245.

${ }^{24}$ Para a presença das abelhas em lugares idílicos, ver Teócrito, Idílios, 1.105 ss. e 7.80-85.
} 
ilustrado na história de Corico, possuidor de um pequeno terreno impróprio para cereais, pecuária ou viticultura que ele transformou num horto ridente, cheio de iguarias não compradas (v. 133: dapibus mensas onerabat inemptis), paraíso para abelhas urbanae, verdadeiro elogio da aurea mediocritas e da política augustana de regresso à pequena agricultura ( $G$. 4.130-141).

Mas, significativamente, a bondade do reino das abelhas é garantida por um elemento exógeno, a mão do apicultor, essencial para a fácil produção de mel e para a boa ordem e preservação do enxame, desde a escolha do local para colocar a colmeia até à intervenção para acabar com as guerras e com os momentos de lazer e voo errático (G. 4.103-108) ${ }^{25}$ :

At cum incerta uolant caeloque examina ludunt contemnuntque fauos et frigida tecta relinquont, instabilis animos ludo prohibebis inani.

Nec magnus prohibere labor: tu regibus alas

eripe; non illis quisquam cunctantibus altum

ire iter aut castris audebit uellere signa.

"Mas quando os enxames voam sem rumo certo e brincam no céu

e não fazem caso dos favos e abandonam os frios tectos,

vedarás a esses ânimos inconstantes a brincadeira fútil.

E não é grande trabalho esse vedar: basta arrancares as asas

aos reis; com eles vagarosos, nenhuma abelha ousará fazer

altos voos ou arrancar estandartes do acampamento.".

\section{Séneca}

No Tratado da Clemência, o grande motivo é exactamente a proposta de inserir entre as uirtutes imperatoriae, e em lugar preeminente, a virtude da clemência, aquela que mais convém a alguém que reina (magis decorum regenti... in maiore praestabitur potestate) e que consiste em não ser prejudicial a ninguém, se se quiser ater à lei da natureza $(C l .1 .19 .1)^{26}$.

E Séneca logo torna visível esse raciocínio, onde o conceito de natureza inclui a exemplaridade do reino dos animais, e dos animais mais pequenos ${ }^{27}$, como modelo para os humanos (Cl. 1.19.2-3):

2. Natura enim commenta est regem, quod ex aliis animalibus licet cognoscere et ex apibus;... et amisso rege totum dilabitur, nec umquam plus unum patiuntur melioremque pugna quaerunt; praeterea insignis regi forma est dissimilisque ceteris cum magnitudine tum nitore.

\footnotetext{
25 Escreve Miles, 1980 , p. 228, a propósito dos versos iniciais de G. 4.8-17: "We learn first of the bees' great vulnerability".

26 Sen. Cl. 1.3.3: Nullum tamen clementia ex omnibus magis quam regem aut principem decet; $1.5 .2:$... clementia omnibus quidem hominibus secundum naturam, maxime tamen decora imperatoribus; cf. 1.8.7; Cic., Off. 1.157, citado supra, Fin. 3.63-64 (tal como as formigas, abelhas, cegonhas, nós, homens natura sumus apti ad coetus, concilia, ciuitates) e Fin. 3.66 (os mais capazes, ad seruandum genus hominum incitantur).

27 Cf. Verg. G. 4.176: si parua licet componere magnis; Ecl. 1.23: si paruis componere magna solebam.
} 
3. ...rex ipse sine aculeo est; noluit illum natura nec saeuum esse nec ultionem magno constaturam petere telumque detraxit et iram eius inermem reliquit. Exemplar hoc magnis regibus ingens; est enim illi mos exercere se in paruis et ingentium rerum docimenta in minima aggerere.

2. "Foi a natureza que inventou o rei, como se pode verificar tanto entre os outros animais como nas abelhas; ...e se o rei se perde, o enxame dispersa-se totalmente; jamais suportam mais do que um e procuram o melhor em combate; além disso, ele é notável pela beleza e é diferente dos outros tanto no tamanho como no brilho. 3. ...quanto ao rei em si, esse não tem aguilhão; a natureza não quis que ele fosse selvático nem que aplicasse punição de grande peso, e não só o privou de aguilhão como ainda deixou a sua ira sem armas. Eis um exemplo poderoso para os grandes reis; é que a natureza tem por costume revelar-se em coisas de pouca monta e, nas mais pequenas, amontoar provas das coisas mais ingentes.".

Este trecho sintetiza, numa perspectiva filosófica de registo estóico, todos os cambiantes ético-políticos do tema das abelhas: modelo dado pela natureza, legitimidade do poder régio, imagem do rei como garante da concórdia, traço utópico na sugestão de uma monarquia primitiva que escolhe o mais forte e o mais belo ${ }^{28}$, proposta de uma governação onde a severidade não existe, antes é a clemência que se torna virtude do governante, extensão da ideologia da solidariedade humana ao próprio enxame, isto é, a todo o sistema organizacional, na medida em que, apesar de dotadas de aguilhão, as abelhas não praticam sevícias em nome de outrem.

\section{Columela}

Quanto ao tratamento do tema das abelhas em Columela, cheio de ecos virgilianos, duas observaçóes prévias se impóem: pimeiramente, a óptica prevalecente, objectiva e utilitarista, em função do destinatário, eivada de cepticismo, arreda as questôes controversas ou subtis: a origem lendária das abelhas, tomada como liberdade poética, e a reprodução sexuada ou assexuada (9.2.2-3), ou por bugonia (9.14.6), são questôes sem interesse prático, argúcias para investigadores e deleite para literatos (9.2.4-5).

Acresce que também é explicitamente apresentada a perspectiva antropomórfica da descrição, logo quando o autor nega a hipótese de partilha do reino (9.9.1-2):

1. Quippe talis est apium natura ut pariter quaeque plebs generetur cum regibus; qui ubi euolandi uires adepti sunt, consortia dedignantur uetustiorum, multoque magis imperia, quippe cum rationabili generi mortalium, tum magis egentibus consilii mutis animalibus nulla sit

\footnotetext{
${ }^{28}$ Esse cambiante primitivo, evocador da idade do ouro, está claramente marcado em Sen. Ep. 90.4.: Sed primi mortalium quique ex his geniti naturam incorrupti sequebantur, eundem habebant et ducem et legem, commissi melioris arbitrio. Naturae est enim potioribus deteriora summittere. Mutis quidem gregibus aut maxima corpora praesunt aut uehementissima... inter homines pro summo est optimum. "Os primeiros homens, os homens da geração seguinte que, ainda incorruptos, obedeciam à natureza, tinham um só chefe e uma só lei: confiar-se às decisôes do melhor, já que a lei natural é que os inferiores se submetam aos melhores. Nos bandos de animais, são os mais fortes ou mais corajosos que assumem a chefia ... entre os homens a chefia competia, não ao mais forte, mas ao moralmente superior”, trad. de Segurado Campos, Séneca, Cartas a Lucílio. Lisboa, 1991.
} 
regni societas. 2. Itaque noui duces procedunt cum sua iunentute... domicilii... propter desiderium sedis... patria.

1. "Na verdade, a natureza das abelhas é tal que a plebe se gera a par com os reis. Estes, logo que alcançam força para voar, desdenham a associação com os mais velhos, e muito mais ainda as suas ordens. $\mathrm{Na}$ verdade, náo existindo partilha de poder para a espécie humana, dotada de razão, por maioria de razão ela também não existe para os animais sem fala, carecidos de discernimento.". 2. "Assim, os chefes novos partem com a sua juventude... do domicílio... por causa do desejo de uma morada... uma pátria.”.

Estes pressupostos explicam algumas das opçóes temáticas do autor, bem como as escolhas vocabulares. De facto, sem prejuízo de apontamentos dispersos, Columela não apresenta nenhuma descrição enfaticamente dedicada, por exemplo, à organização do trabalho entre as abelhas. O que sobreleva é o excesso de trabalho quando as flores abundam, prejudicando a dedicação às crias (9.13.13), obrigação que é paradoxalmente desempenhada pelos zângãos (9.15.1-2), tal como regista, a exemplo de Aristóteles, a tendência para a preguiça, a propósito do controlo da matança dos zângãos (9.15.3):

Nam nec ad occidionem gens interimenda est, ne apes inertia laborent, quae cum fuci aliquam partem cibariorum absumunt, sarciendo damna fiunt agiliores. Nec rursus multitudinem praedonum coalescere patiendum est, ne uniuersas opes alienas diripiant.

"Com efeito, essa raça náo deve ser suprimida até ao aniquilamento, para que as abelhas não caiam na inércia, elas que, quando os zângãos consomem uma parte dos seus alimentos, se tornam mais ágeis a reparar os danos. Também náo se deve aceitar que fique uma multidão de poltrôes, para não desbaratarem recursos alheios.”.

Mas, mesmo neste ponto, é bastante acentuada a intervenção externa do dominus ou do paterfamilias (9.5.2: magis expediet sub oculis domini esse apiarium; 9.7.3: ad utilitatem solius patrisfamiliae), do curator (9.5.3, 9.9.3, 9.14.3), do custos (9.9.12) ou do procurator (9.9.2), marca óbvia da intervenção do homem como factor de progresso e de optimizaçáo dos recursos, numa perspectiva económica dominante.

Verdadeiramente notória é a extrema valorização do tema da governação das abelhas, e em especial a questão do regime político, um regime de monocracia, e portanto um reino (9.9; cf. 9.10.2-3: regnet in aula ... finem regni), onde o rei garante a coesão do enxame, o seu não definhamento, e, por consequência, a sua produtividade. Nessa perspectiva benéfica, onde se descortina uma monarquia de tipo primitivo baseada na superioridade e na beleza (9.10.1-3), trata-se naturalmente de um rei sem aguilhão (sine spiculo) e confinado à colmeia, portanto não saindo para guerrear.

Quando se coloca o problema da sucessão ou da concorrência, particularmente no início da primavera, com o nascimento de um novo enxame, Columela náo esconde a controvérsia. Depois, de referir a conveniência de matar o novo rei para garantir uma coabitação sem discórdia na mesma colmeia, dá conta da teoria contrária (9.11.2-3):

2. Sunt qui seniorem potius regem summouent, quod est contrarium, quippe turba uetustior uelut quidam senatus minoribus parere non censent, atque imperia ualidiorum contumaciter spernendo poenis ac mortibus afficitur. 3. Illi quidem incommodo, quod iuueniori examini solet accidere, cum antiquarum apium relictus a nobis rex senectute defecit et tamquam 
domino mortuo familia nimia licentia discordat, facile occurritur. Nam ex iis aluis quae plures habent principes dux unus eligitur, isque translatus ad eas quae sine imperio sunt rector constituitur.

2. "Há quem suprima antes o rei mais velho, o que é contraproducente, pois a turba mais velha, como que um senado, entende náo obedecer aos mais novos; e, ao menosprezar com contumácia as ordens dos mais fortes, é castigada e condenada à morte.". 3. "Quanto ao inconveniente que costuma acontecer a um enxame mais novo quando o rei das abelhas antigas, por nós preservado, morre de velhice e a família entra em discórdia, por excessiva licença, como pela morte de um senhor -, para isso há remédio fácil. De facto, dos cortiços que têm vários príncipes, escolhe-se um chefe único, o qual, transferido para as abelhas que estão sem órgão de poder, se torna o seu regedor.".

Neste breve passo, e na sua imediata continuação, encontramos notaçóes interessantíssimas: a oposição entre monarquia e anarquia (nimia licentia); a ideia de uma monarquia estrangeira; e, finalmente, a questão da titulatura do governante ideal, onde dos habituais rex e dux se transita para princeps e, sobretudo, para rector, cujo registo teórico, e talvez ciceroniano, não é demais assinalar, embora sempre numa perspectiva de governação régia, cuja alternativa seria de tipo democrático ou anárquico ${ }^{29}$.

A terminologia política é assim marcada por claros resquícios de lutas republicanas (9.9.7: his partibus; 9.11.2: uetustior... senatus; 9.10.7: gratia), evocando inclusive todo o ambiente de guerra civil que caracterizou o final da República e início do Império (9.6.5: dissidentes; 9.6.6: dissidentis reges, seditione; 9.9.5-6: ciuilibus bellis, intestino bello, dissidentibus; 9.9.7: duces seditionum; 9.13.9: seditione, concordes).

Subjaz a tal fraseologia uma perspectiva de organização social em que se entrecruzam essencialmente dois status (plebs vs. proceres, acaso principes); dois níveis etários (iuuentus ou noua agmina vs. turba uetustior, senatus, senectus) que desenvolvem uma dialéctica de poder e dominação, onde o conceito de obediência sofre total inversão ${ }^{30}$; dois estatutos jurídicos colectivos (9.9.6: populus vs. gentes ou exteri), a que corresponde guerra civil e guerra externa; dois valores (9.9.6: concordia vs. discordia) ${ }^{31}$; e talvez até dois regimes, como acima ficou exposto. Vejamos um trecho bem ilustrativo, a propósito dos novos enxames (9.9.6-7), onde o princípio de uma corregência ou colegialidade é claramente tomado como risco:

6. Sunt enim saepe plures unius populi duces, et quasi procerum seditione plebs in partis diducitur, quod frequenter fieri prohibendum est, quoniam intestino bello totae gentes

${ }_{29}$ Col. 9.11.4-5: regii generis proles... popularis notae pulli... regios pullos... plebei seminis; cf. 9.9.2: noui duces; 9.9.6: populi duces; 9.11.5: plebei seminis; 9.12.4: popularis; 9.13.9: peregrinae plebis.

${ }^{30}$ A descrição da anarquia é reminiscente de Cic. Rep. 1.67: "o pai teme o filho, o filho despreza o pai, todo o pudor desaparece, é-se absolutamente livre, nenhuma diferença existe entre cidadáo e estrangeiro, o mestre receia os alunos e com eles é complacente, os alunos desprezam o mestre, os adolescentes arrogam-se o peso da autoridade dos anciáos e, por sua vez, os anciãos regressam aos passatempos dos adolescentes, para lhes não serem odiosos e pesados". (trad. de F. Oliveira, Cícero, Tratado da República, Lisboa, 2008).

${ }^{31}$ Rastreio o termo concordia em 9.13.9 e 9.15.7, a de discordia em 9.9.6 e 9.11.1, mas poderia relacionar também com reconciliare, bona fides, dissidere, seditio. 
consumuntur. 7. Itaque si constat principibus gratia, maneat pax incruenta. Sin autem saepius acie dimicantis notaneris, duces seditionum interficere curabis.

6. "De facto, amiúde existem vários chefes de um só povo, e, tal como numa sedição de próceres, a plebe divide-se em facçôes, mas há que evitar que isto aconteça com frequência, uma vez que naçóes inteiras se destroem com uma guerra interna." 7. "Assim, se existe simpatia entre os príncipes, que perdure uma paz incruenta. Se, pelo contrário, amiúde os observares a entrar em combate, tratarás de matar os chefes das sediçóes.".

Sobressai a questão da titulatura, que, atenta a insistência no tema da sedição, da revolta e da guerra civil, parece ter especial predilecção pela coloração militar de dux (9.9.2: noui duces; 9.9.6: populi duces), que alterna com rex, princeps, rector.

A esta preferência corresponde um acumular de temas disfóricos: para além dos termos ligados às ideias de discórdia, dissensão, sedição, violência e guerra (cf. 9.9.45: militaria signa, Martius canor, pugnam, bellis, proeliantur; cf. v.75: praetoria), surgem ainda termos como iracundia (9.3.3) e ira (9.9.6), os temas da morte e da doença, a tendência para a perversão da ordem pelos mais novos, as inimizades e perigos.

\section{Plínio o Antigo}

No livro XI da História Natural, a excepcionalidade das abelhas é logo marcada pela afirmaçáo de que, de entre todos os insectos, elas ocupam o primeiro lugar e provocam justa e extrema admiração, ademais tendo sido criadas para utilidade do homem (Nat. 11.11: hominum causa genitis; ad usus uitae; Nat. 11.67: munificum animal). Anote-se que o relacionamento com o humano (societas) se baseia na aequitas (Nat. 11.44).

Na primeira caracterização genérica que delas é feita (Nat. 11.11-12), e para além do tema da sua divindade ou excepcionalidade, logo ocorrem alguns dos tópicos mais comuns em Plínio: produzem mel e cera; entregam-se ao trabalho (labor); executam construçóes (opera et labores); têm uma comunidade (res publica); órgãos de aconselhamento privado (consilia priuatim); líderes comuns (duces gregatim); costumes ou regras de conduta (mores); efficacia; industria; energia (neruos, uires); ratio; total devoção ao colectivo (nihil nouere nisi commune), o que as torna superiores aos humanos; e ingenium.

Tal como em Virgílio, encontramos aqui os temas que podem orientar a pesquisa: organização social e política, civilização e costumes, trabalho.

Quanto à organização social e política, não faltam as referências a uma governação monocrática e à figura do governante supremo e único. Mas a questáo da titulatura deste governante assume clara tonalidade epocal, com o termo rex ou dux a ceder a imperator, o qual, inclusive, como que tem um consilium Principis (Nat. 11.29).

Desde a nascença, o rei não apenas recebe morada especial como apresenta traços que nele assinalam um destino invulgar (Nat. 11.48). Com o seu desenvolvimento, mais se acentuam essas marcas, evocando um destino real semelhante ao atribuído às monarquias primitivas, eleitas com base na beleza, na força e na maior estatura ${ }^{32}$.

\footnotetext{
32 Veja-se Lucrécio, 5.1111-1112: pro facie cuiusque et uiribus ingenioque; / nam facies multum ualuit uiresque uigebant.
} 
A gestação de vários reis é bem justificada pelo facto de as abelhas terem uma instintiva consciência da sua necessidade e pela conveniência de seleccionarem o melhor e mais belo (Nat. 11.50-51).

Aos reis são inclusive atribuídas insígnias correspondentes, entre as quais virá a surgir o aguilhão (cf. Nat. 11.60: aculeum apibus dedit natura), que partilham com as obreiras, mas que é assunto de enorme controvérsia e significado ideológico, de que Plínio se distancia (Nat. 11.52):

...non constat inter auctores, rex nullumne solus habeat aculeum, maiestate tantum armatus, an dederit quidem eum natura, sed usum eius illi tantum negauerit. illud constat, imperatorem aculeo non uti.

“...não há unanimidade entre os autores, se o rei é o único que nenhum aguilhão possui, armando-se somente com a sua majestade, ou se a natureza lhe deu um, mas simplesmente lhe negou o seu uso. Numa coisa há unanimidade: o imperador não faz uso de aguilhão.”.

Embora sem explicitar a relação de causa e efeito, Plínio também se debruça sobre a relação entre imperator e súbditos (Nat. 11.52-54):

52. mira plebei circa eum obedientia. 53. cum procedit, una est totum examen circaque eum globatur, cingit, protegit, cerni non patitur. reliquo tempore, cum populus in labore est, ipse opera intus circumit, similis exhortanti, solus inmunis. circa eum satellites quidam lictoresque, adsidui custodes auctoritatis. 54. procedit foris non nisi migraturo examine... cum processere, se quaeque proximam illi cupit esse, in officio conspici gaudet. fessum umeris subleuant, ualidius fatigatum ex toto portant. si qua lassata defecit aut forte aberrauit, odore persequitur. ubicumque ille consedit, ibi cunctarum castra sunt.

52. "Admirável é a obediência da plebe que o cerca.". 53. "Quando ele sai, todo o enxame está junto e aglomera-se à volta dele, protege-o, náo consente que ele seja visto. No tempo restante, quando o povo está no seu trabalho, ele próprio inspecciona as tarefas no interior, como que exortando, sendo o único dispensado. À volta dele, como que acompanhantes e lictores, permanentes guardióes da sua autoridade.". 54. "Não sai para fora senáo quando o enxame está para emigrar... Quando saem, cada uma das abelhas anseia por estar próxima dele, compraz-se em ser observada na sua tarefa. Amparam-no em seus ombros quando cansado, carregam totalmente com ele quando muito fatigado. Se alguma vez desfalece de cansaço ou se perde por casualidade, seguem-no pelo odor. Onde quer que ele pouse, aí todas acampam.".

Todo este passo abunda em terminologia moral e política próxima das relaçóes de poder (obedientia, auctoritatis, in officio) e está eivado de tonalidades militares e de cambiantes romanas (lictores, castra). Não falta sequer a marca da popularidade do rei, que se manifesta ao seu desaparecimento. Nessa ocasião, as abelhas têm verdadeira reacção de afecto, de lamentação fúnebre ${ }^{33}$, e até de quase histeria (Nat. 11.56 e 64):

33 Cf. Nat. 11.63. cum defunctas progerunt funerantiumque more comitantur exequias; Verg. G. 4.255256: tum corpora luce carentum / exportant tectis et tristia funera ducunt; Columela, 9.13.7: ut publico luctu, maesto silentio torpent. Em Ar. HA 626b, a inércia é provocada por uma praga. 
56. duce prenso totum tenetur agmen, amisso dilabitur migratque ad alios. esse utique sine rege non possunt. inuitae autem interemunt eos, cum plures fuere (...) 64. rege ea peste consumpto maeret plebes ignauo dolore, non cibos conuehens, non procedens; tristi tantum murmure glomeratur circa corpus eius. subtrahitur itaque deductae multitudini. alias spectantes exanimem luctum non minuunt; tunc quoque ni subueniatur, fame moriuntur.

56. "Quando o chefe é apanhado, todo o enxame se detém, quando se perde, desfaz-se e migra para outros. De modo algum podem estar sem rei. Porém, contra a vontade, matam-nos quando há vários. (...)". 64. "Se o rei é vítima da peste, a plebe lamenta-se mergulhada numa dor entorpecedora, não recolhendo alimentos, não fazendo surtidas. Unicamente se aglomera em triste murmúrio à volta dele. Por isso ele é subtraído à multidão, que é afastada. De outro modo, enquanto vêem o defunto, não afrouxam o luto. Então, se também não se lhes acudir, morrem de fome.".

Deve anotar-se que o Naturalista conhece a hipótese de na mesma colmeia viverem dois enxames. Mas, nesse caso, afirma tratar-se somente de ocupação de espaço contíguo, mantendo-se a especificidade de cada um deles (Nat. 11.23: cum duo examina concordibus populis dissimiles habuere ritus 'quando dois enxames, com seus povos em concórdia, mantêm costumes diferentes').

Quanto à questão do trabalho, Plínio compraz-se mesmo na explanação das suas tarefas (Nat. 11.20-22), as quais obedecem a um princípio racional (Ratio operis ...; cf. $\$ 25$ : mira obseruatio operis), quase marcial (statio ad portas more castrorum ... cum agmen ad opera processit) ${ }^{34}$, hierarquizado de acordo com a idade (adulescentia, ad opera exeunt ... seniores intus operantur), e se concretizam numa distribuição equitativa e de tipo comunitário, tanto no exterior como no interior da colmeia, o que é bem ilustrado pelo Naturalista com a anáfora aliae, que vem do $\$ 20$ e se alarga até Nat. 11.22:

sunt enim intus quoque officia diuisa: aliae struunt, aliae poliunt, aliae suggerunt, aliae cibum comparant ex eo quod adlatum est; neque enim separatim uescuntur, ne inaequalitas operis et cibi fiat et temporis.

Ora no interior da colmeia as tarefas também estáo divididas: umas dedicam-se à construção, outras fazem a limpeza, outras servem de ajudante, outras preparam a comida com aquilo que lhes é trazido; e não comem separadamente, para que náo haja qualquer desigualdade no trabalho, na comida e no emprego do tempo.

Para além deste apontamento que faz lembrar as syssitia de Esparta ${ }^{35}$, um traço sempre de tonalidade utópica, é tal a obsessão com o trabalho que as abelhas censuram a inércia das que desistem, castigam-nas e punem-nas com a morte (Nat. 11.25), numa actividade censória e justiceira assinalada pelo verbo notare, que evoca a nota censoria.

${ }^{34}$ Cf. Nat. 11.26: castrorum more; Verg. G. 4.67 ss.: ad pugnam... bello... Martius canor; Varr. 3.16.2930: ut milites faciunt, cum castra mouent. A marcialidade da sociedade das abelhas deixa no texto pliniano várias marcas, como quando descreve uma rixa por causa das flores (Nat. 11.58): rapinae... aciem... custos ... dimicant... duasque acies contrarias duosque imperatores instruunt, maxime rixa... dimicatio.

${ }^{35}$ Em Nat. 11.26 também se diz que dormem todas ao mesmo tempo. 
Todavia, Plínio não deixa de lhes permitir momentos de lazer (Nat. 11.68), mas somente os consentidos depois de todas as tarefas terem sido realizadas, e mesmo aí parece tratar-se de algo regulado por rituais solenes; quando se trata de paragem das saídas por causa do mau tempo, as abelhas encontram trabalho alternativo: aproveitam o tempo para fazer as limpezas (Nat. 11.25).

\section{Conclusóes}

As controvérsias científicas existentes, em especial sobre o sexo da rainha, sobre o número de rainhas e sobre a existência e uso do aguilhão pelo rei, e sem prejuízo de uma intensa intertextualidade, permitem a apropriação literária das versóes mais adequadas para situar a mensagem ideológica que se pretende: um rei único ou vários chefes, um rei ou uma rainha, reprodução assexuada ou não.

Encontram-se, deste modo, utilizaçóes simbólicas tấo diversas como a de Xenofonte, que, numa obra genuinamente utópica, a Ciropedia, busca as abelhas para retratar o monarca ideal e, no Económico, para explicar a função da mulher, verdadeira rainha do lar; ou a de Séneca, que claramente utiliza uma versão monocrática do governo do enxame para afirmar ostensivamente que a natureza propóe uma constituição régia; no geral, o elogio do modelo monocrático, embora por vezes de forma mitigada, tem subjacente a ideia da escolha do melhor.

$\mathrm{Na}$ descrição da organização social e da divisão do trabalho das abelhas, onde Virgílio e Plínio sobressaem, é evidente a presença de nítidas pinceladas de utopia sob a forma de comunitarismo de bens, educação dos filhos em comum, ausência de cópula, isto é, de casamento e família, monarquia benévola baseada na beleza, sem prejuízo das hesitaçóes de Aristóteles e do cepticismo de Columela.

A cor civilizacional romana é notória em todo o vocabulário usado pelos autores latinos, quer através de terminologia marcante (aula, colonia, concordia, discordia, imperator, maiestas, plebs, populus, princeps, Quirites, senatus), quer pelo recurso a comparaçóes e imagens, como o do uer sacrum e, em geral, o aspecto marcial do enxame em marcha, com a correspondente terminologia militar. Neste domínio, sobressaem Columela, pela presença de um quadro de referência com laivos republicanos, já presente em Varrão, e Plínio, pela clara adesão ao regime de um imperador.

Apesar de um apontamento sobre locus amoenus evocador de uma idade do ouro, com uma coloração de primitivismo romântico, o elogio do labor impede que se veja na utopia das abelhas uma mera exaltação de um passado utópico ou de uma organização social de tipo primitivo, pois as abelhas também têm marcas disfóricas, rastreadas em Aristóteles, Varrão, Virgílio, Columela e Plínio.

Seria, nesse caso, de exaltar a figura do apicultor, particularmente em Varrão, Virgílio e Columela, uma entidade demiúrgica que reconduz o modelo da natureza à verdadeira senda, impedindo a sua descaracterização ou morte. Será este apicultor uma personificação do governante-médico, o imperador que, em última análise, trará à natureza animal e humana a sua verdadeira felicidade? Ou somente a realidade da submissáo da natureza à vontade e ao saber do homem? 


\section{Bibliografia}

Para os autores antigos citados, e tendo em especial apreço os comentários, no geral adoptei a edição Budé; a excepção foi Plínio o Antigo (Teubner) e Virgílio (Oxford); as traduçóes portuguesas são indicadas em nota, quando utilizadas.

J. Aymard (1960), "L'animal et les vertus 'romaines" in: Hommages L. Herrmann. Bruxelles, pp. 118-123.

J. Béranger (1975), Principatus. Études de notions et d'histoire politiques dans l'Antiquité gréco-romaine. Genève.

R. T. Bruère (1956), "Pliny the Elder and Virgil", CP 51 228-245.

E. Burck (1965), "Das Menschenbild bei Vergil”, in A. Schäfer, Das Menschenbild in der Dichtung. München, pp. 48-83.

A. B. Cook (1985), "The Bee in Greek Mythology", JHS 15.1

H. Dahlmann (1954), Der Bienenstaat in Vergils Georgica. Mainz.

J. Ferguson (1975), Utopias of the Classical World. London.

M. I. Gonçalves (1983), Imagens e simbolos animais na poesia greco-latina. 2 vols. Lisboa.

J. Griffin (1979), "The fourth Georgic, Virgil and Rome”, GR 26 pp. 61-80.

M. Grosse (2006), “Animal Epic”, in H. Cancik - H. Schneider, eds., Brill's Encyclopaedia of the Ancient World. New Pauly. Classical Tradition, I. Leiden, pp. 138-141.

P. A. Johnston (1980), Vergil's Agricultural Golden Age. A Study of the Georgics. Leiden.

G. Lloyd (1983), Science, Folklore and Ideology, Cambridge.

G. B. Miles (1980), Virgil's Georgics. A New Interpretation. Berkeley.

R. A. B. Mynors (2000), Virgil Georgics. Oxford, repr.

Y. Nadeau (1984), “The lover and the Statesman. A study in apiculture (Virgil, Georgics, 4.281-558), in F. Woodman - D. West, Poetry and Politics in the Age of Augustus. Cambridge, pp. 59-82.

C. G. Perkell (1981), “On the Corcyian farmer of Virgil's Fourth Georgic”, PA 111 pp. 167-177.

J. Pollard (1977), Birds in Greek Life and Myth. London.

M. C. J. Putnam (1979), Virgil's Poem of the Earth. Studies in the Georgics. Princeton.

S. Roca (2003), Animali (e uomini) in Cicerone (De nat. Deor. 2, 121-161). Genova.

R. F. Thomas (1988), Virgil, Georgics, vol. 2. Cambridge.

J. M. C. Toynbee (1973), Animals in Roman Life and Art. London.

K. White (1970), Roman Farming. London.

B. G. Whitfield (1956), "Virgil and the bees. A study in ancient agriculture lore", GR 3 99-117.

L. P. Wilkinson (1997), The Georgics of Virgil. A Critical Survey. Bristol. 



\section{Série}

\section{Documentos}

Imprensa da Universidade de Coimbra

Coimbra University Press

2009

- $\mathrm{U}$

C • 